\title{
Validation of the neurofunctional evaluation protocol for Alternative and Augmentative Communication
}

\author{
Ítala da Piedade Queiroz ${ }^{(1)}$ \\ Edênia da Cunha Menezes ${ }^{(1)}$ \\ Ivana Maria Barboza dos Santos ${ }^{(1)}$ \\ Ueslane Melo de Goes ${ }^{(1)}$ \\ Rosana Carla do Nascimento Givigi(1)
}

(1) Universidade Federal de Sergipe, São Cristovão, Sergipe, Brasil.

Research support source: Fundação de Apoio à Pesquisa e à Inovação Tecnológica do Estado de Sergipe - FAPITEC.

Conflict of interests: Nonexistent

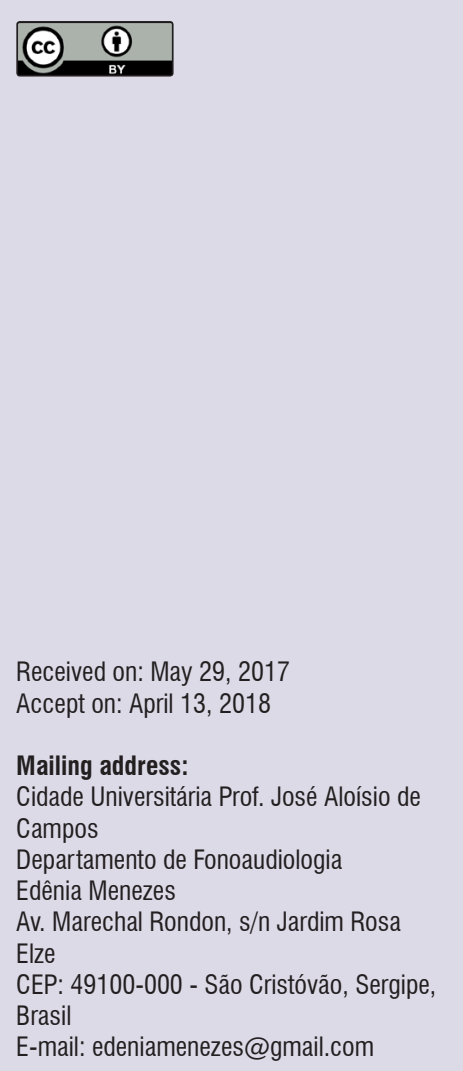

\section{ABSTRACT}

Objective: to validate the neurofunctional evaluation for Alternative and Augmented Communication protocol.

Methods: the study was carried out in four steps: instrument construction, literature review, clinical validation and evaluation of the protocol by field experts, through an interactive questionnaire which was repeatedly applied, until the last set of responses was regarded as satisfactory. In addition, clinical evaluations were performed by applying the protocol in children and adolescents with motor impairment in a clinical trial.

Results: statistical analysis of the protocol application in the therapeutic setting showed the Kappa indices for each observer with an overall mean of 0.436 (moderate agreement), besides the agreement among experts in content evaluation.

Conclusion: agreement between the evaluators, specialists and the protocol clinical application results allowed choosing and implementing an alternative communication resource appropriate to the neuromuscular characteristics of the patient, providing a low cost access, as well as the quick identification of the motor skills that enabled the speech-language therapy.

Keywords: Communication; Disabled Persons; Validation Studies 


\section{INTRODUCTION}

This research articulates areas of Speech, Language and Hearing Sciences that study the Augmentative and Alternative Communication (AAC), Motor Deficiency and the neuromotor aspects that influence access to the AAC. In the process of implementation of the $A A C$, questions arise regarding access to high and low technology instruments for subjects with cerebral palsy and other motor deficiencies. It is understood that the development of language will be more effective once the issues of accessibility to communication are met.

The AAC is based on the Assistive Technology (AT) area, which is defined as an area of knowledge with an interdisciplinary feature, involving resources, strategies, practices and services, aiming to promote functionality, relating it to the participation of people with disabilities in the promotion of autonomy, independence, quality of life and inclusion ${ }^{1,2}$.

Augmentative and Alternative Communication is a subarea of the Assistive Technology and, according to Gonçalves ${ }^{3}$, it arose in clinical practice, from the need to think / find forms of communication for people who could not communicate through speech. According to Bersch $^{4}$, AAC interferes in interpersonal relationship and social insertion, directly assisting in the process of communication and interaction.

The alternative communication resources are diversified, inherent in the specifics of each user, being divided according to complexity and cost, classified in high and low technology. Low-tech features involve low-cost materials with a greater opportunity for access and easy to use, such as adapted books; adapted computer keyboards; and planks formed by pictographic symbols, such as PCS, a system with a limitation of meanings. High-tech instruments, on the other hand, involve high-cost materials such as triggers, vocalizers and software that enable total independence in the communication of their users ${ }^{5}$.

The AAC provides communicative interactions of individuals without orality, being an important tool in the process of language constitution and school interaction, essential for the learning process ${ }^{6,7}$. The use of language is the most important condition for the development of the child's higher psychological structures. The internalization of historically determined and culturally organized contents takes place through language, first on a social, then in an individual level ${ }^{8}$.

It is emphasized that the AAC is not a factor that inhibits speech, since it structures the linguistic functioning of the individual. The development of language, from the socio-historical interactionist perspective, is deprived of determining mechanisms during acquisition. Language is conceived as an instrument responsible for the organization of thought and the social emancipation of the subject, becoming active and a co-author of his / her own development ${ }^{8}$. According to Leontiev, 1988, p. 82:

[...] the child is not limited, in fact, to changing places in the system of social relations. He / she also becomes aware of these relationships and interprets them. The development of their consciousness finds expression in a change in the motivation of their activity; old motives lose their stimulating force, and new ones are born, leading to a reinterpretation of their earlier actions ${ }^{9}$.

The AAC acts in this context as a tool for learning and, thus, guarantees the importance of its implementation in the school context.

The scales developed until then seek to evaluate functions or skills and not the implicit motor performance in the function. The use of ICF (International Classification of Functioning, Disability and Health) by professionals involved in the rehabilitation process increases the quality and the individuality of patient data, since two people with the same disease may present different functional manifestations, and two people with equivalent functional capacity do not necessarily present the same health condition ${ }^{10}$.

There are protocols that evaluate communicative functions with a traditional focus on body structure and function (evaluating speech components, language and hearing problems) in order to classify a person's ability to communicate in real life: Gross Motor Function Classification System (GMFCS), Manual Ability Classification System (MACS) and Communication Function Classification System ${ }^{11}$.

These protocols still do not allow the evaluation focusing on the motor aspects for the initial moment of the implementation process of the Alternative Communication, thus, it is still necessary to validate a specific protocol for the neuromotor aspects of people with motor disabilities. Since $88 \%$ of the children diagnosed with cerebral palsy present communicative alterations ${ }^{12}$, the use of CAA is strongly justified.

The International Classification of Functioning, Disability and Health (IFC) is an internationally used instrument, which considers the subject in his / her singularity, even if it belongs to a similar diagnostic group. The IFC has two divisions, each part consisting 
of two components: the first part refers to Functionality and Disability, which have as components the Body, in which there are two classifications (functions of body systems and structures) and Activities and Participation; the second part refers to the Contextual Factors structured by Environmental Factors and Personal Factors ${ }^{13}$.

The alternative communication is used in this work as a resource to reach the linguistic construction, recognizing the system as one of the alternative forms in the interaction of individuals with neuromotor deficit and taking the language as an interactional function pertinent to the exchanges of experiences between the subjects in structuring their interpersonal relationships. Establishing itself on the work bias in networks with subject, therapy and family, we sought to discuss the aspects involved in this process, using the IFC as a subsidy for construction and application of the protocol of neurofunctional evaluation. In this context, the objective of this study was to validate a neurofunctional assessment protocol for the AAC that would measure muscle tone and functioning in children and adolescents with motor deficits entitled Protocol of Neurofunctional Evaluation for Augmentative and Alternative Communication.

\section{METHODS}

This study has as an ethical contribution the recommended precepts of the Ethics and Research Committee (CEP) involving human beings of the University Hospital of Aracaju of the Federal University of Sergipe, receiving the approval number of 15822613.7.0000.5546 12/28/2013.

The work has a quantitative-qualitative nature and was developed in three phases. The first phase concerns the construction of the instrument that was already in progress in a previous project. Four experts focused the second phase on content review and evaluation. For data collection, a group of experts, preserving the anonymity of individual responses, used the Delphi method from an interactive questionnaire that circulated repeatedly. Necessary documents were prepared for this process, such as the invitation letter, the presentation of the protocol and a data collection instrument containing a questionnaire that was sent to the evaluators.

The third phase included a series of clinical assessments in five patients with the objective of investigating the possible triggers for communication, from the use of the Neurofunctional Assessment Protocol for Choice of Alternative Communication Resource (APPENDIX
A). The Protocol is divided into articulations, voluntary and involuntary movements and reflexes, among other parameters that influence the choice of triggers for the AAC.

The evaluation guided by the protocol was divided into three moments: moment 1 , in which the evaluation is performed through observations during the attendance using low technology; moment 2 , with an evaluation through induction of activities, in order to perform the necessary movements for the analysis - with high technology resources; and moment 3 , with the specific evaluation of the movements. The three moments are applied in a hierarchical way, that is, moment 2 is performed if the data obtained at moment 1 were not enough for the analysis, occurring the same at moment 3 .

The evaluation data were collected according to the qualifier: Function and Structure, being: $\mathrm{F}=$ Force, $\mathrm{R}$ = Resistance, $\mathrm{M}=$ Mobility, $\mathrm{S}=$ Stability, $\mathrm{C}=$ Control, Rig $=$ Rigidity and $\mathrm{Sp}=\mathrm{Spasm}$; ranging from 0 to 4 , being 0 - no deficiency, 1 - mild deficiency, 2 - moderate deficiency, 3 - severe deficiency and 4 - complete deficiency.

The selection of the subjects for the research met the eligibility criteria previously established: to be subjects with motor deficiency between 3 and 20 years old, to have preserved comprehension and presence of language alterations. The patients were selected at the Specialized Rehabilitation Center (SRC). The selection was made based on the medical diagnosis, motor profile and Speech, Language and Hearing Sciences assessment. Participants were included after signing the Free and Informed Consent Term (TCLE).

The last census carried out by the Brazilian Institute of Geography and Statistics (IBGE) for $2010^{14}$, made available by the Health Care Network Coordination (CERAS), was used for the sample calculation of the subjects participating in the research, which indicated the total number of 10470 people with severe motor deficiency in the city of Aracaju. The sample size of 5 (five) individuals was delimited, with an acceptable error of $10 \%$ and a $90 \%$ confidence level.

Three sessions were recommended to carry out the evaluation of the candidates for the use of the alternative communication resource and application of the protocol in the clinical setting.

The neurofunctional evaluation protocol was answered in the therapeutic setting by two evaluators (research students) during the 1st, 2nd and 3rd moments to analyze the levels of 
inter- and intra-evaluator concordance, with the evaluators performing the analysis individually.

\section{Statistical Analysis}

The data of the evaluation in the therapeutic space using the protocol of execution of neurofunctional evaluation to choose an alternative resource of communication were placed in a data sheet of the program Statistical Package for Social Sciences SPSS, version 16.0 , with a significance level of $5 \%$ ( $p>0.05)$. After the data were obtained, Kappa and Shapiro-Wilks tests were performed to verify the normality. The results obtained and classified as parametric analysis were expressed descriptively.

\section{RESULTS}

The construction of the protocol was based on the selection of domains of the CIF that better guided the choice of the resources of Augmentative and Alternative Communication. The chapters were selected using the Neurofunctional Assessment targeting criteria, that is, the chapters that best guided the moment of evaluation, containing relevant items for a precise definition of the resources to be used by each subject.

The selection of CIF items specifically followed two chapters: the 7th - "Funções Neuromusculoesqueléticas e funções relacionadas com o movimento" (Neuromusculoskeletal functions and functions related to movement) and the 2nd - "Funções sensoriais e dor" (Sensory functions and pain), with the articulation of the functions related to the eye in the latter.

From the selected items, five guiding components were chosen for evaluation: $\mathrm{F}=$ Force, $\mathrm{R}=$ Resistance, $\mathrm{M}=$ Mobility, $\mathrm{S}=$ Stability, $\mathrm{C}=$ Control, Rig = Rigidity and $\mathrm{Sp}=$ Spasm. A scale was also adopted - Qualifiers - from 0 to 4, which represented the degree of Function and Structure; these qualifiers were divided into: 0 - No deficiency, 1 - Mild deficiency, 2 - Moderate deficiency, 3 - Severe deficiency, 4 - Complete deficiency.

The protocol had the objective to allow a greater visualization of the data obtained in the neurofunctional evaluation, by joining the items of the CIF, the selected components and the qualified ones, reverberating in specific and concrete data with an evaluation criteria in common for all evaluated subjects.

The first version of the protocol was sent to specialists in the field for possible adjustments. At the end of this adjustment process, a new document, valid in its content and adapted according to the experts' suggestions appeared. The questionnaire for data collection was composed of three parts: the first one refers to the presentation of the research objective and guides to the specialists regarding the filling of the instrument. The second consists in the characterization of specialists with data on sex, age, occupation, place of work, municipality of work, duration of school formation and questions related to professional experience in teaching, research and use of Alternative Communication. The third is the Instrument for the evaluation of the protocol.

In the first round, the specialists received the presentation of the protocol and the instrument of data collection containing a questionnaire and were asked to respond individually with quantitative answers supported by justifications and qualitative information. With each new round, the questions were repeated and the participants re-evaluated their responses from the reformulated protocol according to the answers of the experts from the previous round. New forecasts were requested with justifications, and this process was repeated in the successive rounds of the questionnaire, until the response of the last round was considered with a satisfactory level of agreement. Regarding the interactive questionnaire that circulated among specialists in the field, although it was sent to 33 specialists, only 11 responded to the invitation letter, 7 signed the TCLE, 4 participated in the first round and 3 in the second.

As for titration, half of the experts were doctors and masters and all had specialization in AAC or language (Figure 1). All the experts had experience in the area of AAC, and their activities varied between teaching, assistance and research. 


\begin{tabular}{|c|c|c|c|}
\hline & Occupation & Time of operation & Graduation Degree \\
\hline Specialist 1 & Professor & 38 years old & Doctorate degree \\
\hline Specialist 2 & Clinician & 30 years old & Specialization \\
\hline Specialist 3 & Professor and Clinician & 30 years old & Doctorate degree \\
\hline
\end{tabular}

Figure 1. Description of the experts who participated in content evaluation

The experts answered the following questions in the two rounds. In the second round, the agreement between the evaluators was perceived and possible application bias was clarified, as presented in Table 1 .

Table 1. Descriptive analysis of expert content evaluation

\begin{tabular}{|c|c|c|c|}
\hline & Participants & Round 1 & Round 2 \\
\hline \multirow{3}{*}{$\begin{array}{c}\text { Implementation protocol for neurofunctional evaluation } \\
\text { - Functional Evaluation for Alternative Communication } \\
\text { in Motor Deficiency (ACADM) - representing the } \\
\text { presented content } \\
\end{array}$} & Spe 1 & I Disagree & I agree \\
\hline & Spe 2 & Do not agree or disagree & I agree \\
\hline & Spe 3 & I Disagree & I agree \\
\hline \multirow{3}{*}{$\begin{array}{l}\text { Does it clearly define the definition of neurofunctional } \\
\text { assessment for the implementation of Alternative } \\
\text { Communication? }\end{array}$} & Spe 1 & I disagree & I agree \\
\hline & Spe 2 & Do not agree or disagree & Strongly Agree \\
\hline & Spe 3 & Do not agree or disagree & Do not agree or disagree \\
\hline \multirow{3}{*}{$\begin{array}{l}\text { Is the purpose described consistent with the content of } \\
\text { the protocol? }\end{array}$} & Spe 1 & I disagree & Strongly agree \\
\hline & Spe 2 & Strongly agree & Strongly Agree \\
\hline & Spe 3 & I agree & Do not agree or disagree \\
\hline \multirow{3}{*}{$\begin{array}{l}\text { Is the information contained in this protocol adequate } \\
\text { for the target audience of this protocol? }\end{array}$} & Spe 1 & I agree & Strongly agree \\
\hline & Spe 2 & Do not agree or disagree & Do not agree or disagree \\
\hline & Spe 3 & I agree & Do not agree or disagree \\
\hline \multirow{3}{*}{$\begin{array}{l}\text { Do the general instructions reflect the most relevant } \\
\text { information in the protocol and tell you the step-by-step } \\
\text { how to use it? }\end{array}$} & Spe 1 & I disagree & Strongly agree \\
\hline & Spe 2 & I agree & I agree \\
\hline & Spe 3 & I agree & Do not agree or disagree \\
\hline \multirow{3}{*}{$\begin{array}{l}\text { Can the demonstrated results be achieved with the } \\
\text { protocol? }\end{array}$} & Spe 1 & I disagree & Strongly agree \\
\hline & Spe 2 & Do not agree or disagree & I agree \\
\hline & Spe 3 & Do not agree or disagree & I agree \\
\hline \multirow{3}{*}{$\begin{array}{l}\text { Does the protocol evaluate all the important variables } \\
\text { for the motor aspects that imply the implementation of } \\
\text { the CAA? }\end{array}$} & Spe 1 & I agree & Do not agree or disagree \\
\hline & Spe 2 & I agree & I agree \\
\hline & Spe 3 & I disagree & Do not agree or disagree \\
\hline
\end{tabular}

${ }^{\star}$ Spe $=$ Specialist 
The rounds were finalized with the consensus among the specialists of the final version of the Neurofunctional Assessment Protocol for Choice of Alternative Communication Resource (APPENDIX A). The protocol contains the following variables to be analyzed:

- Function of joints and bones (mobility of the cervical joints, mobility of the shoulder joint, mobility of the wrist joints, mobility of the joints of the hands, mobility of the joints of the feet, mobility of the hip joints, control of voluntary cervical movements, control of voluntary movement of the hand, control of the voluntary movement of the arm, control of the voluntary movement of the lower limbs, control of the right side movement, mobility of the bones of the shoulder, mobility of the bones of the pelvis, mobility of the carpal bones, mobility of the shoulder blade bones, mobility of the tarsal bones and general control of the joints);

- Muscle functions (functions related to muscle strength of the head, functions related to muscular strength of the upper limbs, functions related to muscular strength of the lower limbs, functions related to muscular strength of the hands, functions related to muscular strength of the feet and functions related to muscle strength);

- Functions related to movement (functions related to postural reflexes, functions related to stretching tonic reflexes, hyperreflexia, hyporreflexia, functions related to involuntary movements, stereotypies and perseveration);

- Vision and related functions (acuity, field, binocular, monocular, eyelid and direction).

In addition to these variables, the following items were included as suggested by experts in the area:

Functional Conclusion (low-tech features: board, looking board, table, panels, book, binder, folder, album; high tech features: mouse, eye tracker, keyboard hive, vocalizer, computer, tablet and pressure trigger );

Possible creative movements for triggers (blinking, aiming, cervical movement, shoulder movement, blowing, jaw movement, hand movement, wrist movement, arm movement, finger movement, leg movement, foot movement, toe movement and pointing).

Regarding the neurofunctional evaluations of the therapeutic setting, 7 subjects were evaluated, among the children / adolescents who started the project. Of those, 5 completed the neurofunctional evaluation using the protocol, the others were turned off because they did not fit the intended profile. Another part of the selected subjects did not participate in the study due to non-attendance or difficulty in access.

Neurofunctional evaluation of the subjects with the qualifiers chosen by the evaluators (Table 2): 
Table 2. Analysis of the clinical findings of the protocol

\begin{tabular}{|c|c|c|c|c|c|c|c|c|c|c|}
\hline \multirow[b]{2}{*}{ Functions of Joints and Bones } & \multicolumn{2}{|c|}{ Patient 1} & \multicolumn{2}{|c|}{ Patient 2} & \multicolumn{2}{|c|}{ Patient 3} & \multicolumn{2}{|c|}{$\begin{array}{ll}\text { Patient } 4 \\
\end{array}$} & \multicolumn{2}{|c|}{ Patient 5} \\
\hline & Th1 & Th2 & Th1 & Th2 & Th1 & Th2 & Th1 & Th2 & Th1 & Th2 \\
\hline Mobility of cervical Joints & 2 & 3 & 1 & 0 & 4 & 4 & 4 & 4 & 1 & 1 \\
\hline Stability of cervical joints & 3 & 2 & 3 & 2 & 4 & 4 & 4 & 4 & 3 & 4 \\
\hline Control of Cervical Joints & 2 & 3 & 3 & 1 & 4 & 4 & 4 & 4 & 3 & 3 \\
\hline Mobility of the shoulder joint & 3 & 3 & 3 & 3 & 4 & 4 & 3 & 4 & 1 & 2 \\
\hline Stability of shoulder joints & 3 & 2 & 3 & 4 & 4 & 4 & 4 & 4 & 2 & 3 \\
\hline Control of shoulder joints & 3 & 2 & 3 & 3 & 4 & 4 & 3 & 4 & 3 & 3 \\
\hline Mobility of wrist joints & 2 & 2 & 3 & 2 & 4 & 4 & 4 & 4 & 0 & 0 \\
\hline Stability of wrist joints & 2 & 3 & 3 & 3 & 4 & 4 & 4 & 4 & 2 & 2 \\
\hline Control of wrist Joints & 2 & 2 & 3 & 2 & 4 & 4 & 4 & 4 & 3 & 3 \\
\hline Mobility of joints of the hands & 2 & 3 & 3 & 1 & 4 & 4 & 4 & 4 & 0 & 0 \\
\hline Stability of joints of the hands & 2 & 3 & 3 & 2 & 4 & 4 & 4 & 4 & 2 & 2 \\
\hline Control of joints of the hand & 2 & 3 & 3 & 3 & 4 & 4 & 4 & 4 & 3 & 2 \\
\hline Mobility of the joints of the feet & 3 & 3 & 0 & 0 & 4 & 4 & 4 & 4 & 3 & 2 \\
\hline Stability of the joints of the feet & 3 & 3 & 1 & 1 & 4 & 4 & 4 & 4 & 3 & 3 \\
\hline Control of the joints of the feet & 3 & 3 & 1 & 1 & 4 & 4 & 4 & 4 & 3 & 2 \\
\hline Mobility of hip joints & 3 & 4 & 3 & 4 & 4 & 4 & 4 & 4 & 3 & 4 \\
\hline Stability of hip joints & 3 & 3 & 3 & 4 & 4 & 4 & 4 & 4 & 3 & 4 \\
\hline Control of hip joints & 3 & 3 & 3 & 4 & 4 & 4 & 4 & 4 & 3 & 4 \\
\hline Control of voluntary cervical movement - only & 2 & 4 & 3 & 2 & 3 & 4 & 4 & 4 & 2 & 3 \\
\hline Control of voluntary cervical movement - multiple & 1 & 4 & 3 & 2 & 3 & 4 & 4 & 4 & 3 & 4 \\
\hline Control of voluntary cervical movement - mobility & 2 & 4 & 3 & 0 & 3 & 4 & 4 & 4 & 2 & 1 \\
\hline Control of voluntary cervical movement - stability & 2 & 3 & 3 & 2 & 3 & 4 & 4 & 4 & 3 & 4 \\
\hline Control of voluntary cervical movement - control & 2 & 3 & 3 & 1 & 3 & 4 & 4 & 4 & 3 & 3 \\
\hline Control of voluntary hand movement - only & 2 & 2 & 3 & 2 & 4 & 4 & 4 & 4 & 2 & 2 \\
\hline Control of voluntary hand movement - multiple & 1 & 2 & 3 & 3 & 4 & 4 & 4 & 4 & 3 & 3 \\
\hline Control of voluntary hand movement - mobility & 2 & 2 & 3 & 2 & 4 & 3 & 4 & 4 & 1 & 2 \\
\hline Control of voluntary hand movement - stability & 2 & 3 & 3 & 2 & 4 & 4 & 4 & 4 & 2 & 2 \\
\hline Control of voluntary hand movement - control & 2 & 2 & 3 & 3 & 4 & 4 & 4 & 4 & 2 & 1 \\
\hline Control of voluntary arm movement - only & 3 & 3 & 3 & 3 & 4 & 4 & 4 & 4 & 1 & 2 \\
\hline Control of voluntary arm movement - multiple & 1 & 2 & 3 & 3 & 4 & 4 & 4 & 4 & 2 & 3 \\
\hline Control of voluntary arm movement - mobility & 2 & 3 & 3 & 3 & 4 & 4 & 4 & 4 & 1 & 2 \\
\hline Control of voluntary arm movement - stability & 2 & 3 & 3 & 3 & 4 & 4 & 4 & 4 & 2 & 2 \\
\hline Control of voluntary arm movement - control & 2 & 3 & 3 & 3 & 4 & 4 & 4 & 4 & 2 & 1 \\
\hline Control of voluntary movement of the lower limbs - only & 2 & 4 & 1 & 1 & 4 & 4 & 4 & 4 & 2 & 2 \\
\hline Control of voluntary movement of the lower limbs - multiple & 1 & 4 & 1 & 1 & 4 & 4 & 4 & 4 & 2 & 1 \\
\hline Control of voluntary movement of the lower limbs - mobility & 2 & 3 & 1 & 0 & 4 & 4 & 4 & 4 & 2 & 2 \\
\hline Control of voluntary movement of the lower limbs - stability & 2 & 3 & 1 & 1 & 4 & 4 & 4 & 4 & 3 & 3 \\
\hline Control of voluntary movement of the lower limbs - control & 2 & 3 & 0 & 1 & 4 & 4 & 4 & 4 & 2 & 3 \\
\hline Control of the right side movement - only & 2 & 3 & 1 & 2 & 4 & 4 & 4 & 4 & 1 & 1 \\
\hline Control of the right side movement - multiple & 2 & 3 & 1 & 2 & 4 & 4 & 4 & 4 & 3 & 3 \\
\hline Control of the right side movement - mobility & 2 & 2 & 1 & 2 & 4 & 4 & 4 & 4 & 1 & 2 \\
\hline Control of the right side movement - stability & 2 & 3 & 1 & 3 & 4 & 4 & 4 & 4 & 2 & 3 \\
\hline Control of the right side movement - control & 2 & 3 & 1 & 2 & 4 & 4 & 4 & 4 & 2 & 2 \\
\hline Mobility of bones of the shoulder blade & 2 & 2 & 3 & 3 & 4 & 4 & 4 & 4 & 2 & 2 \\
\hline Stability of bones of the shoulder blade & 2 & 4 & 3 & 4 & 4 & 4 & 4 & 4 & 2 & 3 \\
\hline Control of bones of the shoulder blade & 2 & 4 & 3 & 3 & 4 & 4 & 4 & 4 & 2 & 3 \\
\hline Mobility of pelvic bones & 4 & 4 & 3 & 3 & 4 & 4 & 4 & 4 & 3 & 3 \\
\hline Stability of pelvic bones & 4 & 4 & 3 & 3 & 4 & 4 & 4 & 4 & 3 & 4 \\
\hline Control of pelvic bones & 4 & 4 & 3 & 3 & 4 & 4 & 4 & 4 & 3 & 4 \\
\hline Mobility of carpal bones & 4 & 3 & 2 & 3 & 4 & 4 & 3 & 4 & 0 & 0 \\
\hline Stability of carpal bones & 4 & 4 & 3 & 3 & 4 & 4 & 3 & 4 & 0 & 0 \\
\hline Control of carpal bones & 4 & 4 & 3 & 3 & 4 & 4 & 3 & 4 & 0 & 0 \\
\hline
\end{tabular}




\begin{tabular}{|c|c|c|c|c|c|c|c|c|c|c|}
\hline \multirow[b]{2}{*}{ Functions of Joints and Bones } & \multicolumn{2}{|c|}{ Patient 1} & \multicolumn{2}{|c|}{ Patient 2} & \multicolumn{2}{|c|}{$\begin{array}{l}\text { Patient } 3 \\
\end{array}$} & \multicolumn{2}{|c|}{$\begin{array}{ll}\text { Patient } 4 \\
\end{array}$} & \multicolumn{2}{|c|}{ Patient 5} \\
\hline & Th1 & Th2 & Th1 & Th2 & Th1 & Th2 & Th1 & Th2 & Th1 & Th2 \\
\hline Mobility of tarsal bones & 4 & 3 & 0 & 0 & 4 & 4 & 3 & 4 & 2 & 2 \\
\hline Stability of tarsal bones & 4 & 4 & 0 & 0 & 4 & 4 & 4 & 4 & 2 & 3 \\
\hline Control of tarsal bones & 4 & 4 & 0 & 0 & 4 & 4 & 4 & 4 & 2 & 2 \\
\hline General joint control - mobility & 3 & 3 & 2 & 2 & 4 & 4 & 3 & 4 & 2 & 2 \\
\hline General joint control - stability & 3 & 3 & 2 & 2 & 4 & 4 & 4 & 4 & 3 & 3 \\
\hline Muscle Functions & Th1 & Th2 & Th1 & Th2 & Th1 & Th2 & Th1 & Th2 & Th1 & Th2 \\
\hline Functions related to muscle strength of the head - Isotonic & 0 & 3 & 3 & 2 & 4 & 4 & 0 & 0 & 3 & 3 \\
\hline Functions related to muscle strength of the head - Hypotonic & 0 & 0 & 3 & 2 & 4 & 4 & 1 & 1 & 3 & 3 \\
\hline Functions related to muscle strength of the head - Hypertonia & 3 & 4 & 3 & 0 & 4 & 4 & 0 & 0 & 0 & 0 \\
\hline Functions related to muscle strength of the head - Isolated & 0 & 2 & 3 & 3 & 4 & 4 & 1 & 1 & 2 & 2 \\
\hline Functions related to muscle strength of the head - group & 0 & 2 & 3 & 3 & 4 & 4 & 1 & 3 & 3 & 3 \\
\hline Functions related to muscle strength of the head - force & 3 & 2 & 3 & 3 & 4 & 4 & 3 & 3 & 3 & 3 \\
\hline Functions related to muscle strength of the head - resistance & 3 & 4 & 3 & 3 & 4 & 4 & 3 & 3 & 3 & 3 \\
\hline Functions related to muscular strength of the upper limbs - isolated & 2 & 3 & 1 & 3 & 4 & 4 & 4 & 4 & 1 & 2 \\
\hline Functions related to muscular strength of the upper limbs - group & 2 & 2 & 1 & 3 & 4 & 4 & 4 & 4 & 2 & 2 \\
\hline Functions related to muscular strength of the upper limbs - force & 2 & 1 & 3 & 3 & 4 & 4 & 4 & 4 & 1 & 1 \\
\hline Functions related to muscular strength of the upper limbs - resistance & 2 & 3 & 3 & 3 & 4 & 4 & 4 & 4 & 2 & 2 \\
\hline Functions related to muscular strength of the lower limbs - isolated & 3 & 4 & 0 & 0 & 4 & 4 & 4 & 4 & 2 & 3 \\
\hline Functions related to muscular strength of the lower limbs - group & 3 & 4 & 0 & 0 & 4 & 4 & 4 & 4 & 3 & 3 \\
\hline Functions related to muscular strength of the lower limbs - force & 3 & 4 & 0 & 0 & 4 & 4 & 4 & 4 & 3 & 3 \\
\hline Functions related to muscular strength of the lower limbs - resistance & 3 & 4 & 0 & 0 & 4 & 4 & 4 & 4 & 3 & 4 \\
\hline Functions related to muscular strength of the hands - isolated & 4 & 2 & 3 & 1 & 4 & 4 & 4 & 4 & 1 & 1 \\
\hline Functions related to muscular strength of the hands - group & 4 & 2 & 3 & 1 & 4 & 4 & 4 & 4 & 1 & 1 \\
\hline Functions related to muscular strength of the hands - force & 2 & 1 & 3 & 0 & 4 & 4 & 4 & 4 & 1 & 1 \\
\hline Functions related to muscular strength of the hands - rigidity & 2 & 2 & 3 & 3 & 4 & 4 & 4 & 4 & 1 & 1 \\
\hline Functions related to muscular strength of the feet - isolated & 2 & 4 & 0 & 0 & 4 & 4 & 3 & 4 & 2 & 3 \\
\hline Functions related to muscular strength of the feet - group & 3 & 4 & 0 & 0 & 4 & 4 & 4 & 4 & 3 & 3 \\
\hline Functions related to muscular strength of the feet - force & 3 & 4 & 0 & 0 & 4 & 4 & 4 & 4 & 2 & 3 \\
\hline Functions related to muscular strength of the feet - resistance & 2 & 4 & 0 & 1 & 4 & 4 & 3 & 4 & 2 & 3 \\
\hline Functions related to muscle strength - right side & 2 & 1 & 3 & 3 & 4 & 4 & 3 & 4 & 2 & 2 \\
\hline Functions related to muscle strength - left side & 3 & 2 & 2 & 3 & 4 & 4 & 3 & 4 & 3 & 3 \\
\hline Functions related to muscle strength - inferior half & 2 & 2 & 1 & 2 & 4 & 4 & 3 & 4 & 3 & 3 \\
\hline Functions related to muscle strength - all the limbs & 3 & 2 & 3 & 3 & 4 & 4 & 3 & 4 & 2 & 3 \\
\hline Functions related to movement & Th1 & Th2 & Th1 & Th2 & Th1 & Th2 & Th1 & Th2 & Th1 & Th2 \\
\hline Functions related to reflexes - postural reflexes & 4 & 3 & 3 & 4 & 4 & 4 & 3 & 3 & 4 & 4 \\
\hline functions related to stretching tonic reflexes & 3 & 3 & 3 & 3 & 4 & 4 & 2 & 3 & 1 & 1 \\
\hline Hyperreflexia & 4 & 4 & 3 & 3 & 4 & 4 & 2 & 2 & 1 & 1 \\
\hline Hyporreflexia & 0 & 0 & 3 & 0 & 4 & 4 & 0 & 0 & 0 & 0 \\
\hline Functions related to involuntary movements & 4 & 3 & 3 & 2 & 4 & 4 & 2 & 4 & 2 & 1 \\
\hline Stereotypies and perseveration & 0 & 4 & 1 & 0 & 4 & 4 & 0 & 0 & 0 & 0 \\
\hline Vision and related functions & Th1 & Th2 & Th1 & Th2 & Th1 & Th2 & Th1 & Th2 & Th1 & Th2 \\
\hline Acuity & 0 & 0 & 0 & 0 & 1 & 0 & 0 & 0 & 0 & 0 \\
\hline Field & 0 & 0 & 0 & 0 & 1 & 1 & 0 & 0 & 2 & 2 \\
\hline Binocular & 0 & 0 & 0 & 0 & 1 & 1 & 0 & 0 & 0 & 0 \\
\hline Monocular & 0 & 0 & 0 & 0 & 1 & 1 & 0 & 0 & 0 & 0 \\
\hline Eyelid & 0 & 0 & 0 & 0 & 2 & 1 & 3 & 3 & 1 & 2 \\
\hline Direction & 0 & 0 & 0 & 0 & 3 & 3 & 0 & 0 & 2 & 1 \\
\hline
\end{tabular}

Subtitle: Therapist evaluation: Kappa indexes for each observer with a general average of 0.436 (moderate agreement). * Th $=$ Therapist 
The statistical analysis of the data collected in the neurofunctional evaluation in the clinical space results in Kappa indexes for each observer with a general mean of 0.436 (moderate agreement). Therefore, the protocol is reproducible. Since there was an agreement among the evaluators, the items of the protocol were kept. The data presented normal distribution according to the Shapiro Wilk test.

Descriptive analysis with the profile characterization of the subjects and alternative resource chosen:

Patient 1: 14 years old, male, with mild motor alteration, low-tech alternative resource - board with pictographic symbols.

Patient 2: 13 years old, male, mild motor alteration, low-tech alternative resource - board with pictographic symbols.

Patient 3: 10 years old, male, severe motor alteration, high-tech alternative resource - infrared light beam placed on the spectacle frame (without lenses) triggered by blinking eyes.

Patient 4: 10 years old, male, diagnosed with Tay Sachs syndrome, severe motor impairment, high-tech alternative - accelerometer sensor triggered with eyebrow movement.

Patient 5: 5 years old, female, severe motor alteration, high-tech alternative resource - pressure trigger triggered by hand-closing movement.

\section{DISCUSSION}

One of the greatest challenges was to obtain the sample size of the subjects and the unfamiliarity of professionals with the competence established by the research, such as not mastering the subject, not knowing the methodology used, among others ${ }^{15}$.

The fact that the protocol has been evaluated by experts with academic qualifications, according to Galdeana and Rossi ${ }^{16}$, increases the credibility of the data. The performance of professionals in both the public and private spheres favors the analysis of the indicators from different point of views, considerably enriching the validation process by the content validation strategy ${ }^{15}$.

The choice of triggers as an alternative communication resource opens a range of possibilities for these subjects. Children with lack of speech, but users of alternative communication systems are able to understand and make themselves understood in the world of language. It can be achieved through looks, gestures, facial expressions and body posture, allowing their interaction with others and a greater insertion in society ${ }^{17-19}$.

In the literature, it is found that children, youngsters and adults with oral and written communication difficulties need the help of supplementary and / or alternative communication to broaden communicative exchanges, acquire new communicative skills and thus broaden the range of interlocutors in other social contexts ${ }^{20-25}$.

The alternative resource acts as an instrument of communication and interaction with the other, providing subjects with a better quality of life, as shown by an article published by the group, with an initial version of the protocol ${ }^{26}$.

\section{CONCLUSION}

It is believed that the protocol developed will have positive implications for clinical practice, since the neurofunctional evaluation following the developed protocol allowed the choice and implementation of an alternative communication resource more appropriate to the patient's neuromuscular characteristics.

The application of this evaluation protocol in the clinical routine would allow, in a quick and low cost way, to identify which components of the motor functions or abilities are to be developed or to control and thus to implement the therapeutic action - being able to communicate represents improvement in the quality of life of individuals with serious, motor and linguistic limitations. It would bring dominance in areas such as acquisition of biological quantities, data processing, and creation of interfaces for interaction and integration of systems. This set of knowledge may be the basis for extending the current project or generating new projects. The study of neurofunctionality in subjects with motor impairment can define strategies of use for the CAA.

\section{REFERENCES}

1. Rocha EF, Castiglioni MC. Reflections on technological resources: aids techniques, assistive technology, technology of assistance and technology of support. Rev. Ter. Ocup. Univ. São Paulo. 2005;16(3):97-104.

2. Berberian AP, Krüger $S$, Guarinello AC, Massi GAA. A produção do conhecimento em fonoaudiologia em comunicação alternativa. Rev. CEFAC. 2009;11(2):258-66. 
3. Gonçalves MJ. Comunicação alternativa na fonoaudiologia: uma área em expansão. Rev. CEFAC. 2008;10(3):1-2.

4. Bersch RCR. Introdução à tecnologia assistiva. Porto Alegre: Centro Especializado em Desenvolvimento Infantil (CEDI). 2008. [acesso em 2017 jan.] Disponível em: http:// www.assistiva. com.br.

5. Liegel LA, Gogola MMR, Nohama P. Layout de teclado para uma prancha de comunicação alternativa e ampliada. Rev. Bras. Ed.Esp. 2008;14(3):479-96.

6. Guarda NS da, Deliberato D. Caracterização dos enunciados de um aluno não-falante usuário de recurso suplementar de comunicação durante a construção de histórias. Rev. Bras. Ed. Esp. 2006;12(2):269-88.

7. Paula KMP de, Enumo SRF. Avaliação assistida e comunicação alternativa: procedimentos para a educação inclusiva. Rev. bras. educ. espec. 2007;13(1):3-26.

8. Vigotski LS, Luria AR, Leontiev AN. Linguagem, desenvolvimento e aprendizagem. São Paulo: Editora Ícone, 1988.

9. Leontiev AN. Uma contribuição à teoria do desenvolvimento da psique infantil. In: Vigotski LS, Luria AR, Leontiev NA (Orgs). Linguagem, desenvolvimento e aprendizagem. São Paulo: Editora ĺcone, 1988. p. 82.

10. OMS. CIF: Classificação Internacional de Funcionalidade, Incapacidade e Saúde. São Paulo: EDUSP; 2003.

11. Hidecker MJ, Paneth N, Rosenbaum PL, Kent $\mathrm{RD}$, Lillie J, Eulenberg JB et al. Developing and validating the communication function classification system for individuals with cerebral palsy. Dev. Med. Child. Neurol. 2011;53(8):704-10.

12. Eliasson AC, Krumlinde-Sundholm L, Rösblad B, Beckung E. The Manual Ability Classification System (MACS) for children with cerebral palsy: scale development and evidence of validity and reliability. Dev Med Child Neurol. 2006;48(7):549-54.

13. CCOMS - Centro Colaborador da Organização Mundial da Saúde para a Família de Classificações Internacionais (org). Coordenação da tradução de Cassia Maria Buchalla. CIF: Classificação Internacional de Funcionalidade, Incapacidade e Saúde. São Paulo. EDUSP. 2003.

14. BRASIL. Instituto Brasileiro de Geografia e Estatística - IBGE. Censo demográfico 2010:
População residente por tipo de deficiência, segundo a situação do domicílio, o sexo e os grupos de idade - Amostra - Características Gerais da População - Brasil, 2010.

15. Bessa MEP. Elaboração e validação de conteúdo do protocolo de Intervenções de enfermagem para idosos com risco fragilidade [tese]. Fortaleza (CE): Universidade Federal do Ceará, Faculdade de Farmácia, Odontologia e Enfermagem, Programa de Pós-Graduação em Enfermagem; 2012.

16. Galdeana LE, Rossi LA. Validação de conteúdo diagnóstico: critérios para seleção de expertos. Ciênc. Cuidado e Saúde. 2006;5(1):60-6.

17. Takase EM, Chun RYS. Comunicação e inclusão de crianças com alterações de linguagem de origem neurológica na perspectiva de pais e educadores. Rev. Bras. Educ. Espec. 2010;16(2):251-64.

18. Tetzchner SV, Brekke KM, Sjøthun B, Grindheim E. Inclusão de crianças em educação pré-escola regular utilizando comunicação suplementar e alternativa. Rev. Bras. Educ. Espec. 2005;11(2):151-84.

19. Silva MO. Comunicação alternativa no Brasil: pesquisa e prática. Rev. Bras. Educ. Espec. 2008;14(2):327-8.

20. Deliberato D, Manzini EJ. Identification of the communicative abilities of brazilian children with cerebral palsy in the family context. Communication Disorders Quarterly. 2012;33(4):195-201.

21. Berberian AP, Krüger S, Guarinello AC, Massi GA. A produção do conhecimento em fonoaudiologia em comunicação cuplementar e/ou alternativa: análise de periódicos. Rev. CEFAC. 2009;11(supl2):258-66.

22. Chun RYS. Comunicação suplementar e/ou alternativa: favorecimento da linguagem de um sujeito não falante. Pró-Fono R. Atual Cient. 2003;15(1):55-64.

23. Trevizor TT, Chun RYS. O desenvolvimento da linguagem por meio do Sistema Pictográfico de Comunicação. Pró-Fono R. Atual. Cient. 2004;16(3):323-32.

24. Almeida MA, Piza MHM, Lamônica DAC. Adaptation of the picture exchange communication system in a school context. Pró-Fono R. Atual. Cient. 2005;17(2):233-40.

25. Eskelsen MW, Pacheco FB, Montibeller CG, Blasi HF, Fleig R. Introdução e desenvolvimento do uso da comunicação alternativa na síndrome de Angelman: estudo de caso. Rev. CEFAC. 2009;11(2):228-36. 
26. Melo U, Menezes EC, Givigi RCN. Neurofunctional assessment protocol as a guide to the AAC tools selection in subjects with cerebral palsy. Distúrb. Comum. 2017;29(1):133-43. 


\section{APPENDIX A - PROTOCOL (FINAL VERSION)}

\section{Neurofunctional assessment protocol for choice of alternative communication resource}

\begin{tabular}{|c|c|c|}
\hline \multicolumn{3}{|c|}{ Functions of Joints and Bones } \\
\hline & Qualifier & Moment \\
\hline Mobility of the cervical joints & $M() S() C()$ & \\
\hline Mobility of the shoulder joint & $M() S($ ) C ( ) & \\
\hline Mobility of wrist joints & $M() S($ ) $C(1)$ & \\
\hline Mobility of the joints of the hands & $M() S($ ) C ( ) & \\
\hline Mobility of the joints of the feet & $M() S() C()$ & \\
\hline Mobility of hip joints & $M() S($ ) C ( ) & \\
\hline Control of voluntary cervical movement & $\begin{array}{l}\text { Only ( ) Multiple ( ) } \\
\text { M ( ) S ( ) C ( ) }\end{array}$ & \\
\hline Control of voluntary movement of the hand & $\begin{array}{l}\text { Only ( ) Multiple ( ) } \\
\text { M ( ) S ( ) C ( ) }\end{array}$ & \\
\hline Control of the voluntary movement of the arm & $\begin{array}{l}\text { Only ( ) Multiple ( ) } \\
M(\text { ) S ( ) C ( ) }\end{array}$ & \\
\hline Control of voluntary movement of the lower limbs & $\begin{array}{l}\text { Only ( ) Multiple ( ) } \\
M(\text { ) S ( ) C ( ) }\end{array}$ & \\
\hline Control of the right side movement & $\begin{array}{l}\text { Only ( ) Multiple ( ) } \\
\text { M ( ) S ( ) C ( ) }\end{array}$ & \\
\hline Mobility of the shoulder blade bones & $M() S($ ) C ( ) & \\
\hline Mobility of the bones of the pelvis & $M() S($ ) C ( ) & \\
\hline Mobility of carpal bones & $M() S() C($ ) & \\
\hline Mobility of tarsal bones & $M() S($ ) $C($ ) & \\
\hline General control of the joints & $M() S()$ & \\
\hline & & \\
\hline & Qualifier & Moment \\
\hline Functions related to the muscular strength of the head & $\begin{array}{c}\text { Isotonic ( ) } \\
\text { Hypotonic ( ) Hypertonic( ) } \\
\text { Isolated ( ) Group ( ) } \\
\text { F( ) R( ) }\end{array}$ & \\
\hline Functions related to muscular strength of the upper limbs & $\begin{array}{c}\text { Isolated ( ) Group ( ) } \\
F(\text { ) } R(\text { ) }\end{array}$ & \\
\hline Functions related to muscle strength of the lower limbs & $\begin{array}{c}\text { Isolated ( ) Group ( ) } \\
F() \mathrm{R}(\mathrm{)}\end{array}$ & \\
\hline Functions related to muscle strength of hands & $\begin{array}{c}\text { Isolated ( ) Group ( ) } \\
F(\text { ) } R(\text { ) }\end{array}$ & \\
\hline Functions related to the muscular strength of the feet & $\begin{array}{c}\text { Isolated ( ) Group ( ) } \\
F(\text { ) } R(\text { ) }\end{array}$ & \\
\hline Functions related to muscle strength & $\begin{array}{l}\text { Right Side D ( ) Left Side( ) } \\
\text { Lower Half ( ) All Limbs ( ) }\end{array}$ & \\
\hline Functior & ient & \\
\hline & Qualifier & Moment \\
\hline Functions related to postural reflexes & & \\
\hline Functions related to stretching tonic reflexes & & \\
\hline Hyperreflexia & & \\
\hline Hyporreflexia & & \\
\hline Functions related to involuntary movements & & \\
\hline Stereotypes and perseveration & & \\
\hline
\end{tabular}




\begin{tabular}{|l|}
\hline \multicolumn{1}{|c|}{ Vision and related functions } \\
\hline Acuity \\
\hline Field \\
\hline Binocular \\
\hline Monocular \\
\hline Eyelid \\
\hline Direction \\
\hline
\end{tabular}

\begin{tabular}{|c|c|}
\hline \multicolumn{2}{|c|}{ Functional conclusion } \\
\hline \multicolumn{2}{|c|}{ Low-Tech Resources } \\
\hline Board & YES ( ) NO ( ) WITH ADAPTATION ( ) \\
\hline Looking board & YES ( ) NO ( ) WITH ADAPTATION ( ) \\
\hline Table & YES ( ) NO ( ) WITH ADAPTATION ( ) \\
\hline Panels & YES ( ) NO ( ) WITH ADAPTATION ( ) \\
\hline Book & YES ( ) NO ( ) WITH ADAPTATION ( ) \\
\hline Binder & YES ( ) NO ( ) WITH ADAPTATION ( ) \\
\hline Folder & YES ( ) NO ( ) WITH ADAPTATION ( ) \\
\hline Album & YES ( ) NO ( ) WITH ADAPTATION ( ) \\
\hline \multicolumn{2}{|c|}{ High-tech resources } \\
\hline Computer Mouse & YES ( ) NO ( ) WITH ADAPTATION ( ) \\
\hline Eye tracker & YES ( ) NO ( ) WITH ADAPTATION ( ) \\
\hline Keyboard Hive & YES ( ) NO ( ) WITH ADAPTATION ( ) \\
\hline Vocalizer & YES ( ) NO ( ) WITH ADAPTATION ( ) \\
\hline Computer & YES ( ) NO ( ) WITH ADAPTATION ( ) \\
\hline Tablet & YES ( ) NO ( ) WITH ADAPTATION ( ) \\
\hline Pressure Trigger & YES ( ) NO ( ) WITH ADAPTATION ( ) \\
\hline \multicolumn{2}{|c|}{ Possible creative movements for triggers } \\
\hline Blinking & YES ( ) NO ( ) \\
\hline Aiming & YES ( ) NO ( ) \\
\hline Eyebrow Movement & YES ( ) NO ( ) \\
\hline Cervical movement & YES ( ) NO ( ) \\
\hline Shoulder movement & YES ( ) NO ( ) \\
\hline Blowing & YES ( ) NO ( ) \\
\hline Jaw movement & YES ( ) NO ( ) \\
\hline Hand movement & YES ( ) NO ( ) \\
\hline Wrist movement & YES ( ) NO ( ) \\
\hline Arm movement & YES ( ) NO ( ) \\
\hline Finger movement & YES ( ) NO ( ) \\
\hline Leg movement & YES ( ) NO ( ) \\
\hline Foot movement & YES ( ) NO ( ) \\
\hline Toe movement & YES ( ) NO ( ) \\
\hline Pointing & YES ( ) NO ( ) \\
\hline
\end{tabular}

Subtitle: 1st Moment: Evaluation during the time of therapy - low technology (Observation); 2nd Moment - Functional evaluation with induced activities so that the movement happens - high technology; 3rd Moment - Specific evaluation - with the researcher of computer science. Qualifier: Function and Structure: 0 No deficiency; 1 Mild deficiency; 2 Moderate deficiency; 3 Severe deficiency; 4 Complete disability. F = Force $\mathrm{R}=$ Resistance $\mathrm{M}=$ Mobility St $=\mathrm{Stability} \mathrm{C}=\mathrm{Control}$ Rig $=$ Rigidity $\mathrm{Sp}=$ Spasm 